\title{
Specifics of Psychological, Social and Physical Health Levels Interrelation among Teachers of Different Age and Teaching Experience
}

\author{
Rezeda M. Khusainova ${ }^{1}$ \\ ${ }^{1}$ Kazan (Volga region) Federal University, Kazan, Russia \\ Correspondence: Rezeda M. Khusainova, Kazan (Volga region) Federal University, Kremlyovskaya Street 18, \\ Kazan 420008, Russia.
}

Received: October 24, 2014 Accepted: December 3, 2014 Online Published: December 18, 2014

doi:10.5539/res.v7n1p166 URL: http://dx.doi.org/10.5539/res.v7n1p166

\begin{abstract}
Thematic justification of teachers' psychological health is caused by the fact that its violation poses the essential problem of psychological services in education. The purpose of the article is to study specifics of psychological, social and physical health levels interrelation among teachers of different age and teaching experience. The main method of studying this issue is the ascertaining experiment. Consideration of the components of psychological health was based on psychological distinguishing such levels as psychological (supposed the adequate attitude to health on cognitive, emotional and motivation-behavioral levels); social (defined by the presence of formed communicative qualities and specifics of interpersonal interaction); physical (supporting psychological health due to the functioning of energy structures). Comparative analysis of correlation structures revealed the dominant objective laws of interrelation of selected indicators on the psychological, physical and social health levels, as well as their specifics in groups of teachers with different teaching experience. Depending on the age and teaching experience psychological or physical health indicators become the "core" of the correlation pleiad.

The obtained results allow speaking about a marked impact of the psychological health level on the components of social and physical levels. Immediate practical importance has the generated group of methods, which allow objective and quick diagnosing of psychological health in the condition of teachers health monitoring and thereby improving the efficiency of its correction.
\end{abstract}

Keywords: psychological health, physical health, social health, teaching experience

\section{Introduction}

The health of education workers is one of the fundamental problems of modern society. Specifics of modern life and teaching profession itself requires teachers to have a number of personality qualities that are important for a competent fulfilling of functional duties, while to be able to maintain health (Mokaeva, 2010).

The essence of the concept "health", considered in the article, according to the hierarchical levels of integral individuality on the biological, psychological and social levels, is defined in terms of the identification and disclosure of the criteria content of physical, psychological, psychic and social health, which serve as means of health diagnostics.

At present time this concept is considered at three levels of human functioning: biological, psychological, social, and increasingly the subject of study becomes psychological and social health. Existing diversity in statements and approaches to the concept "health" fits in four models: the medical, biomedical, biosocial and value-social. Medical, biomedical models include physical and psychic health. Biosocial, value-social models include social and psychological health.

In accordance with the logic of the system-subject approach adopted in psychology (Abulkhanova \& Berezina, 2001, Slobodchikov \& Shuvalov, 2001, Bajanova, 2013) the health is understood as an integral component of an integrated system, determined by a number of multi-level factors introducing the feasibility of the concept "psychological health". Psychological health is closely connected with the highest manifestation of the human spirit and allows you to select the psychological aspect of the personal health problems in contrast to the medical, sociological, philosophical and other aspects. 
Generalization of different view-points and our own understanding of the given phenomenon allow to determine the psychological health as an integral characteristic of personal well-being, including cognitive-evaluative component of the biological, psychological and social levels of its manifestation, where the exceptional role for higher psychological formations, performing the functions of the organization, regulation, supporting the integrity of life way.

\section{Materials and Methods}

\subsection{Brief Description of the Organization and Research Methods}

On the basis of theoretical analysis the consideration of the psychological health components was conducted on the basis of distinguishing the following levels: psychological-supposed the adequate attitude to health, on cognitive, emotional and motivation-behavioral levels understood as the degree of regulation and self-regulation, as well as the integration of the teacher personality in the emotional-volitional, value-motivational and intellectual spheres; social-defined by the presence of formed communicative qualities and specifics of interpersonal interaction; physical - supporting psychological health due to the functioning of energy structures.

The following methods were used for diagnostic purposes: the methodic of S. Deryabo and V. Yasvin "Index relation to health; multi-factor R. Cattel's questionnaire which is designed to measure 16 Personality Factors; Eysenck Personality Questionnaire $(E P Q)$ is designed to examine the manifestation degree of personality traits nominated as major components of personality; the methodic of Ch. D. Spilberger and Yu. L. Hanin "Anxiety scale" was developed to measure the level of anxiety; the Herman-Shalven test diagnoses specific features of the individuum neuro-type; Ya.Strelyau temperament questionnaire is designed to investigate the basic peculiarities of the nervous system; the functional systems energy test (Aminev \& Aminev) which allowes us to determine what system is changing under the influence of emotions (Boyko, 1991). In general, there were studied the data of 53 indicators. There was used the Student's t-test to establish the reliability of the differences in the data of teachers psychological health.

\section{Results and Discussions}

The empirical base comprises diagnostic data of Russian schoolteachers (85 people) with teaching experience from 2 months to 34 years. The sample is represented by women. There were created four groups of teachers united on the work experience at school: 0-7 years' work experience; 8-15 years' work experience; 16-24 years' work experience; 25-34 years' work experience.

\subsection{Comparative Analysis of the Quantitative Values of the Studied Data}

Comparative analysis of the quantitative values of the studied data revealed a significant difference between the data of psychological health among teachers of all groups.

A significant number of differences between groups of teachers with experience from 0 to 7 years and teachers with experience from 8 to 15 years refer to the psychological level.

When comparing teachers with 0-7 years' work experience and teachers with 16-24 years' work experience, there is recorded a greater number of significant differences, which are equally distributed between the psychological and the physical levels. Anxiety as the person's quality is more typical for teachers with 16-24 years' work experience. We fix the reduction of emotional expression of teachers with 16-24 years' work experience compared to teachers with 0-7 years' work experience.

\subsection{Student's T-Test Statistical Comparison of Indicators}

Statistical comparison of indicators for Student's t-test when comparing data of teachers with 0 to 7 years work experience and teachers with 25-34 years' work experience has let us to note 15 significant differences in the psychological and physical levels. For example, increasing the value of the t-test in indicator of "expert" reveals a higher level of professional skills of teachers with 25-34 years' work experience compared to teachers with 0-7 years' work experience. Thus, lowering the indicator "communicator" in interpersonal relationships can be shown in authority, sometimes aggressiveness, which is associated with high confidence in the correctness backed by rich experience. The outlined previously "emotional restraint" of teachers with 16-24 years' work experience is already a part of the personal characteristics of teachers with experience over 25 years.

When comparing teachers with 8-15 years' work experience to teachers with 16-24 years' work experience are recorded statistically significant differences, most of which relates to the psychological level. For example, in factor B (Intellect) there is fixed a reduction of indicator. We believe this testifies a tendency to slow learning. Psychophysiological process of adults development is heterogeneous and contradictory. The age of teachers with 16-24 years' work experience belongs to the third macro period in the development of memory, thinking, 
attention. Change of ups and downs in the level of development of thinking suggests unevenness and cyclicality of its development from age to age. Thus, lower values of the indicator in the factor "intelligence" reflect the general trend of psychophysiological development of adults. Experimental studies of psychic functions age changes of people aged 41-46, carried out by several authors (Rybalko 2001; Chirkina 2014), showed that the active learning and self-education maintain them at a high level of development and create the best potential for a more productive cognitive activity (Nigmatullina \& Boltakova, 2014). So professional training of educators is especially necessary for teachers in this group. The increase of the t-test in factor L (credulity-suspiciousness) is expressed in increasing the degree of differences in terms of alertness, wariness, high level of anxiety and concern. The increase of the t-test on XI meridian (bladder) indicates higher values of susceptibility to neuropsychiatric disorders (Luvsan, 1991). Statistically significant differences at $r \leq 0.01$ on the scale of neuroticism confirm the regulation that persons with high neuroticism differ in emotional lability, hyperactivity, slowly return to the original state after the emotional affects. Thus, teachers with 16-24 years' work experience are characterized by high self-control, underestimating their capabilities, diminution their competence, anxiety. They are characterized by a tendency to slow learning, so professional training of educators is essential to preserve the psychological health of the teacher and his/her professionalism. In social contacts it is observed formality and narrowing of the social circle, emotional detachment. In general, this group of teachers is characterized by chronic stress, so it is most vulnerable in terms of maintaining psychological health.

The comparison of indicator for the teachers with 8-15 years' work experience and ones with 25-34 years' work experience there are the most significant differences in the physical level: differences remain in terms of indicator II (colon), IV (spleen-pancreas) meridians and agitation scale. Also, differences remain on the factor Q1 (conservatism-radicalism), "communicator". Reduction in the indicator on factor "communicator" of teachers with 25-34 years' work experience shows a possible emotional stinginess, lack of desire to build long relationships with others.

Analysis of the Student's t-test value when comparing data of teachers with 16-24 years' work experience and with 25-34 years' work experience allows you to record statistically significant differences in the parameters, most of which relate to the psychological level. Significant differences remain unchanged on scales Q1 (conservatism-radicalism), "communicator", excitement, IV meridian (spleen-pancreas), there are added differences in factors Q3 (low-high self-control), neuroticism, even-temperedness.

\subsection{The Research of Interactions Character of Studied Indicators}

The next stage of the analysis of the empirical data was devoted to the research of interactions of studied indicators. As a result of the correlation analysis for each of four groups there were obtained intercorrelation matrixes reflecting the correlation structure of internal and external links of indicators.

In the group of teachers with 0-7 years' work experience recorded 30 straight and 32 inverse significant links in which 47 of 53 indicators are "involved". Analysis of inter-level relations shows the greatest number of identified links between indicators of psychological and physical levels - 17 links. Between the psychological and social levels there are recorded 7 links. Between social and physical levels are identified 12 links. Central backbone indicator which has the most number of links is a factor I (sensibility) - 13 links, reflecting the psychological aspects of health. (Other indicators have less weight in the structure). Thus, personal anxiety - 7 links, and (communicativeness) - 5 links, XII meridian (liver) - 5 linkss, excitement - 4 links.

Another number of significant links of psychological health indicators and indicators of physical and social levels, as well as another their character is found in the analysis of intercorrelation matrix of teachers groups with 8-15 years' work experience. The number of statistically significant correlation coefficients decreases. The total number of direct links is 32 , inverse - 25 (46 interrelated indicators). The backbone indicator has the most number of links in the group is on a physical level, it is IX meridian (pericardium), it is associated with 9 indicators. Psychological health level has fewer links: B (intelligence) - 5, situational anxiety - 5, personal anxiety, $\mathrm{H}$ (shyness) - on 4. Compared with the previous group in the structure of a described group enhanced the status of the physical level, this shows the increase of physical health links indicators. Variety of connections is recorded between psychological and physical levels - 22 interlevel links, between the psychological and social levels - 6 interlevel links, between the social and the physical level 8 interlevel links.

In the group of teachers with 16-24 years' work experience the nature of relations between psychological, social and physical health parameters is somewhat different. A total of 31 direct and 36 inverse links (pairs are formed by 45 indicators). The backbone indicator personal anxiety (10 links) is on the psychological level; other indicators have less weight: IV (spleen - pancreas) - 7 links, VII (bladder) - 6, III (stomach) - 6, IX (pericardium) - 6, “expert” (35) - 6 links, Q2 (suggestibility) - 5, Q3 (self-control) - 5, XII (liver) - 5 links. There are revealed 
19 external links between psychological and physical levels, 6 external links between psychological and social levels of health, 7 external links between social and physical health.

In the group of teachers with experience of 25 to 34 years the backbone indicators are on a psychological level: "expert" - 9 links, extra / introversion - 8, other indicators have less weight in the structure: G (unprincipled) - 5 links, I (sensibility) - 5 links, VIII meridian (kidney) - 5 bonds, O (anxiety), psychoticism - on 4 links, C (emotional stability) - 3 links. In the described structure 29 straight and 28 inverse links are fixed. Variety of links are recorded between psychological and physical health levels -14 interlevel links, between psychological and social level of health - 9 links, between the social and the physical levels - 9 links. Thus, depending on the age and teaching experience, the "core" of correlation pleiad become psychological indicators (I, III and IV groups of teachers), or indicators of physical (II group) level of psychological health.

Psychological level is closely connected with the physical one of those teachers who have the least work experience ( $0-7$ years). In the groups with higher professional work experience this law is significantly transformed. In the group of teachers with experience of 8-15 years the strongest interrelation of the psychological together with the physical level is concentrated in the field of body energy indicators, what is practically not observed in the previous group, where are more substantial links of the psychological level with the indicators of neuro type and temperament. This data confirms that the average age ( $\sim 35$ years $)-$ the border, where health care is becoming a necessity forced to correct one's poor health. In the group of teachers with experience of 16-24 years the links recorded in the previous group are saved, but they become less stable, and in the group with the work experience of 25-34 years - their number decreases. With the age a person perceives his physical condition not so acutely, so its value goes on the back burner.

Similarly there were analyzed the laws of interrelations of psychological state level with the components of social level. The increase of links tightness between these levels in groups with more work experience is fixed.

\section{Conclusion}

The results of indicator comparison of all test groups show the high sensitivity personality factors and health, reflecting the energy potential of the organism to changes in the age and work experience of teachers. In general, a comparative analysis of correlation structures reveals the dominant laws of indicators interrelation distinguished at the psychological and physical levels, as well as their specifics in groups of teachers with different experience of teaching.

Thus, the correlation analysis showed that there is a close relationship of psychological, physical and social health levels, which make to consider their indicatores as forming a single symptom complex. In this case the psychological level in the overall structure of psychological health may be considered as dominant.

As in the theoretical model, presented by the structure of psychological health, the psychological level, in our opinion, is located on a higher hierarchical level, so one can say about its impact on downstream. Accordingly, these received results let us speak about a marked influence of the psychological level on the components of social and physical levels.

\section{References}

Abulkhanova, K. A., \& Berezina, T. N. (2001). Time identity and lifetime (p. 304). SPb., Aletheia.

Bayanova, L. F. (2013). Vygotsky's Hamlet: The dialectic method and personality psychology (pp. 35-42). Psychology in Russia: State of the Art 6.

Boiko, V. V. (1996). Energy of emotions in communication: A look at oneself and others (p. 472). Moscow: Filin.

Chirkina, S. E. (2014). Motives of training activities as a factor of the adults training efficiency during the vocational retraining. Life Science Journal, 11(12), 444-447.

Luvsan, G. (1991). Essays on the eastern reflexology techniques (p. 432). Nauka, Novosibirsk, Siberian Branch.

Mokaeva, M. A. (2010). Psychological health of educator as a condition for its effective activity. Pedagogy education in Russia, 3, 37-41.

Nigmatullina, I. A., \& Boltakova, N. I. (2014). Lifelong learning as an actual strategy of higher professional education modernization in Russia (in case of teacher-logopedists'training). Life Science Journal, 11(11s), 267-274.

Rybalko, E. F. (2001). Age and differential psychology (p. 224). SPb. Piter.

Slobodchikov, V. I., \& Shuvalov, A. V. (2001). Anthropological approach to the solution of children psychological health problems. Questions of psychology, 4, 91-105. 


\section{Copyrights}

Copyright for this article is retained by the author(s), with first publication rights granted to the journal. This is an open-access article distributed under the terms and conditions of the Creative Commons Attribution license (http://creativecommons.org/licenses/by/3.0/). 